\title{
Identification of strain diversity and phylogenetic analysis based on two major essential proteins of Orf viruses isolated from several clinical cases reported in Malaysia
}

\begin{abstract}
There is a little information on the characterization of Orf virus strains that are endemic in Malaysia. The relationship between the severity of disease and the molecular genetic profile of Orf virus strains has not been fully elucidated. This study documented the first confirmed report of contagious ecthyma causing by Orf virus in goats from a selected state of eastern peninsular Malaysia. The disease causes significant debilitation due to the inability of affected animals to suckle which brings a great economic loss to the farmers. A total of 504 animals were examined individually to recognize the affected animals with Orf lesion. Skin scrapping was used to collect the scab material from the infected animals. The presence of Orf virus was confirmed by combination of methods including virus isolation on vero cells, identification by Transmission Electron Microscopy (TEM) and molecular technique using PCR and Sanger sequencing. The results showed the successful isolation of four Orf virus strains with a typical cytopathic effects on the cultured vero cells line. The morphology was confirmed to be Orf virus with a distinctive ovoid and criss cross structure. The phylogenetic analysis revealed that these isolated strains were closely related to each other and to other previously isolated Malaysian orf viruses. In addition these Orf virus strains were closely related to Orf viruses from China and India. This study provides more valuable insight in terms of genotype of Orf virus circulating in Malaysia.
\end{abstract}

Keyword: Orf virus; Orf011; Orf020; PCRTEM; Phylogenetic analysis 